\title{
Strouhal number of bridge cables with ice accretion at low flow turbulence
}

Research · April 2016

DOI: $10.13140 / R G \cdot 2 \cdot 1 \cdot 4004.6481$

CITATIONS

0

1 author:
READS

95

\section{Stanislav Pospisil}

Institute of Theoretical and Applied Mechanics, Academy of Sciences of the Czech Republic 53 PUBLICATIONS 134 CITATIONS

SEE PROFILE

Some of the authors of this publication are also working on these related projects:

New Integrated Knowledge based approaches to the protection of cultural heritage from Earthquake-

Project induced Risk-NIKER View project 


\title{
Strouhal number of bridge cables with ice accretion at low flow turbulence
}

\author{
Piotr Górski ${ }^{* 1}$, Stanislav Pospišil ${ }^{2}$, Sergej Kuznetsov ${ }^{2}$, Marcin Tatara ${ }^{1}$ and \\ Ante Marušićc,3 \\ ${ }^{1}$ Department of Road and Bridges, Faculty of Civil Engineering and Architecture, Opole University of \\ Technology, 45-061 Opole, Katowicka 48, Poland \\ ${ }^{2}$ Institute of Theoretical and Applied Mechanics, Academy of Sciences of the Czech Republic, Czech Republic \\ ${ }^{3}$ Faculty of Mechanical Engineering and Naval Architecture, University of Zagreb, Croatia
}

(Received May 4, 2015, Revised January 9, 2015, Accepted January 15, 2015)

\begin{abstract}
The paper concerns with the method and results of wind tunnel investigations of the Strouhal number (St) of a stationary iced cable model of cable-supported bridges with respect to different angles of wind attack. The investigations were conducted in the Climatic Wind Tunnel Laboratory of the Czech Academy of Sciences in Telč. The methodology leading to the experimental icing of the inclined cable model was prepared in a climatic section of the laboratory. The shape of the ice on the cable was registered by a photogrammetry method. A section of an iced cable model with a smaller scale was reproduced with a $3 \mathrm{D}$ printing procedure for subsequent aerodynamic investigations. The $S t$ values were determined within the range of the Reynolds number (Re) between $2.4 \cdot 10^{4}$ and $16.5 \cdot 10^{4}$, based on the dominant vortex shedding frequencies measured in the wake of the model. The model was oriented at three principal angles of wind attack for each of selected $R e$ values. The flow regimes were distinguished for each model configuration. In order to recognize the tunnel blockage effect the $S t$ of a circular smooth cylinder was also tested. Good agreement with the reported values in the subcritical Re range of a circular cylinder was obtained. The knowledge of the flow regimes of the airflow around an iced cable and the associated $S t$ values could constitute a basis to formulate a mathematical description of the vortex-induced force acting on the iced cable of a cable-supported bridge and could allow predicting the cable response due to the vortex excitation phenomenon.
\end{abstract}

Keywords: bridge cable; ice accretion; Strouhal number; angle of attack; vortex shedding frequency

\section{Introduction}

The excitation mechanism of cables of cable-supported bridges and associated boundary conditions have been extensively researched in the last fifteen years and reported in many papers (Bartoli et al. 2006, Impollonia et al. 2011, Jakobsen et al. 2012, Matsumoto et al. 2001, Wardlaw 1990). A thorough analysis of the dynamic wind response of such structures requires that the vortex-shedding excitation, the buffeting due to wind gusting, the dry inclined cable galloping instability, the wake interference, and the rain-wind induced vibrations should be considered. Such

*Corresponding author, Ph.D., E-mail: p.gorski@po.opole.pl

Copyright $\odot 2016$ Techno-Press, Ltd.

http://www.techno-press.org/?journal=was\&subpage =8

ISSN: 1226-6116 (Print), 1598-6225 (Online) 
phenomena become more significant for cables longer than $100 \mathrm{~m}$. A theoretical background and proposals of the mathematical description of the wind excitation components are presented in respective monographs (Dyrbye and Hansen 1997, Flaga 2008, Flaga 2011). Therefore, for bridge cables with a circular cross-section, such phenomena are relatively well understood.

However, in some weather conditions, the circular cross-section of the cables may change due to ice accretion (see Fig. 1). In this case, the full-scale monitoring of slender bridge elements proves that ice accretion on the bridge cables has a significant influence on the flow field around the cables and their aerodynamics and can lead to a much larger amplitude of cable vibrations under wind action than without the ice ("dry" cable). In the paper (Gjelstrup et al. 2007), the vibrations of an ice-accreted hanger of the Great Belt Suspension Bridge in Denmark due to the wind are reported. The respective vibration amplitudes of the iced hanger, recorded on March 29, 2001, were approximately $1.4 \mathrm{~m}$ in the across-wind direction and approximately $1.0 \mathrm{~m}$ in the along-wind direction. It is notable that such large vibration amplitudes are not observed in the case of a "dry" hanger, i.e., without ice, because they may lead to an excessive stress in the cable structure as well as its joints and may be the principal cause of the material fatigue of cables. The prediction of the possibility of large-amplitude vibrations in iced cables due to the wind requires the knowledge of the existing conditions during the airflow around the iced cables and a thorough explanation of causes of the wind load acting on them. For this reason, the investigation of icing's influence on the aerodynamics of the bridge cables is a very important issue in considering the safety of cable-supported bridges.

In the case of a cable with ice, an asymmetric airflow appears around the cable, creating an asymmetric distribution of the wind pressure on its surface. For this reason, three aerodynamic coefficients, i.e., drag, lift and moment coefficients, depending on the angle of the wind attack should be taken into account. Moreover, in such conditions, an aero-elastic instability of the iced cable known as galloping instability may occur if the specific criteria proposed by den Hartog (1932) are met. It is well documented that the amplitude of galloping of ice-accreted cables can be very large (Gjelstrup et al. 2012).

The analysis of the vortex excitation response of iced cables requires, among other things, knowledge of the Strouhal number (St), which characterizes the vortex-shedding frequency. It is necessary for the determination of the critical wind velocity at which the largest amplitudes due to vortex excitation are observed. The value of $S t$ depends on the shape of the ice accreted on a cable under specific conditions, the cable motion, and the turbulence intensity of an approaching flow and may in some cases depend on the Reynolds number $(R e)$ determining the flow regimes for structures with circular cross-sections.
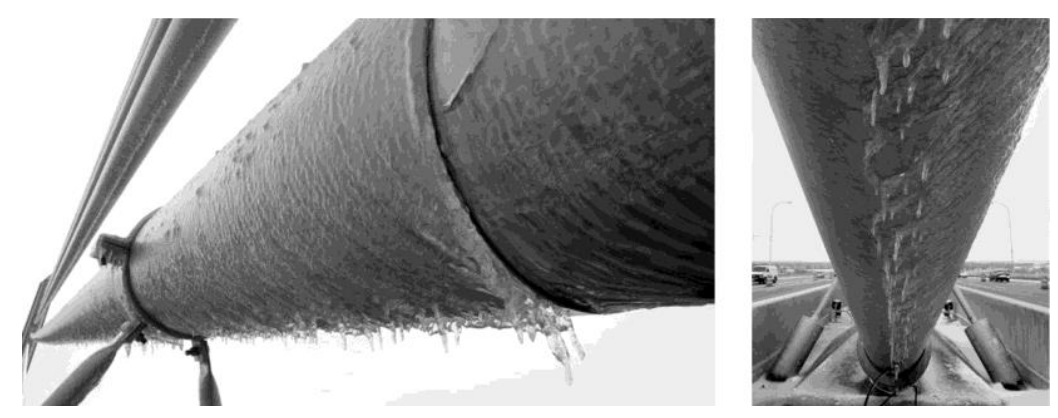

Fig. 1 Example of an iced cable on the cable-supported Veteran's Glass City Skyway Bridge in Toledo, Ohio, USA (website http://www.toledoblade.com) 
In the literature, there exist specific papers on the ice formation (Huang et al. 2011, Wagner and Peil 2011), the modelling of transmission line icing (Makkonen 1998, Fu et al. 2006), the determination of the amplitude of wind-induced vibrations (Gurung et al. 2002), the investigations of $S t$ (Zdero and Turan 2010), the aerodynamic coefficients, and the galloping instability (Waris et al. 2008, Zhitao et al. 2013) of iced electrical power cables. However, because of the relatively small outer diameter of electrical power cables, not exceeding several centimetres, and the different shape of the ice, the results are inappropriate for the cables of cable-supported bridges with larger diameters, usually between ten and several tens of centimetres.

The results from wind tunnel tests conducted to simulate, study, and document ice accretion under specific climatic conditions, comparable to observations of large amplitude cable vibrations in nature, were described in Koss et al. (2012). The influence of the boundary conditions such as the exposure time, the air temperature, the wind velocity, and the droplet mean volume diameter were tested on different shapes of iced vertical or horizontal circular cylinders with a diameter of $3.81 \mathrm{~cm}$, made of polished aluminium, and $8.9 \mathrm{~cm}$, made of machined stainless. In several papers (Gjelstrup et al. 2012, Demartino et al. 2013b, Koss and Lund 2013, Koss et al. 2013), investigations of the influence of ice accretion on the galloping instability of circular cylinders with diameters of 7.0 and $16.0 \mathrm{~cm}$ oriented vertically or horizontally were presented. The aerodynamic coefficients as functions of the angle of wind attack were also determined. It was proven that the galloping instability of the iced cylinders is possible within a small range of angles of wind attack. It should be indicated, that the experimental icing investigations described in the papers (Gjelstrup et al. 2012, Koss et al. 2012, Demartino et al. 2013b, Koss and Lund 2013, Koss et al. 2013) were not performed on inclined models, though the inclination of a cable during the icing process has a significant influence on the ice shape and subsequently on the aerodynamics of the iced cable.

Recently, some papers (Demartino et al. 2015, Demartino and Ricciardelli 2015, Demartino et al. 2013a) described pioneering work on the effects of ice accretion due to in-cloud icing on the aerodynamics of vertical and inclined cylinder models with diameters of $16.0 \mathrm{~cm}$, representing bridge hangers or stay cables. In these papers, extensive studies are reported on the ice accretion processes and the final shapes of ice on these models. The mean aerodynamic force coefficients of the iced bridge cables were also measured. It found that they are significantly affected by the characteristics of ice accretion, depending on the climatic conditions, and that ice accretion can lead to instability phenomena of the bridge cables. It should be noted that the literature on the influence of icing on the aerodynamics of the cables of cable-supported bridges is still insufficient, and it is therefore very advisable and valuable to conduct further studies to quantify the cable aerodynamic variation due to ice accretion. In the above mentioned papers the effect of ice accretion on $S t$ and vortex excitation was not investigated.

The aim of this paper is to present the method and the results of wind tunnel investigations of $S t$ on a stationary iced cable model with respect to different angles of wind attack. The experiments were carried out in the Climatic Wind Tunnel Laboratory of the Czech Academy of Sciences in Telč (website http://cet.arcchip.cz/wind-laboratory-en) using rain sprinklers simulating the real situation during frozen rainy conditions. The methodology leading to the experimental icing of the inclined cable model in a climatic section of the laboratory was prepared. As the wind direction and the atmospheric conditions are variable in time, ice accretion was simulated in one particular weather condition often experienced in Central Europe. The shape of the ice on the cable was registered by a photographic method combined with numerical image analysis. For the aerodynamic investigations, an iced cable model on a smaller scale was reproduced using a 3D 
printing procedure. The $S t$ values were determined within the range of $R e$ between $2.4 \cdot 10^{4}$ and $16.5 \cdot 10^{4}$, based on the dominant vortex-shedding frequencies measured in the wake behind the model. The model was oriented at three principal angles of wind attack for selected values of $R e$. The flow regimes for each model configuration were distinguished. In order to recognize the effects of tunnel blockage, the St values of a circular smooth cylinder was also tested. Good agreement was obtained with the generally reported values in the subcritical $R e$ range of a circular cylinder. The knowledge of the flow regimes of the airflow around the iced cable and the associated $S t$ values could constitute a basis to formulate a mathematical description of the vortex-induced force acting on the iced cable of a cable-supported bridge and could allow the prediction of the cable response due to the vortex excitation phenomenon.

\section{Wind tunnel facility}

The closed-circuit wind tunnel used in this study consists of two sections, a climatic and an aerodynamic section (see Fig. 2), with controlled wind velocity and temperature conditions. The climatic section of the laboratory has a rectangular cross-section that is $2.5 \mathrm{~m}$ in height, $3.9 \mathrm{~m}$ in width and $9.0 \mathrm{~m}$ in length. Using a cooling or heating system, the air temperature may change within the range of $-5^{\circ} \mathrm{C}$ to $+30^{\circ} \mathrm{C}$ in a relatively short time period. In this section, the wind velocity range is from 0.8 to $18 \mathrm{~m} / \mathrm{s}$ (depending on the position of the vertically moveable ceiling and flow nozzle). The rain intensity together with the size of the rain drops may be regulated to simulate effects corresponding to drizzle or heavy rain.

The aerodynamic section also has a rectangular cross-section with a height of $1.8 \mathrm{~m}$ and a width of $1.9 \mathrm{~m}$. The appropriate flow development section is $11.0 \mathrm{~m}$ long to assure the appropriate simulation of the atmospheric boundary layer. The wind velocity range is from 1.5 to $33 \mathrm{~m} / \mathrm{s}$. A ventilator with a power of $200 \mathrm{~kW}$ propels the airflow in the anticlockwise direction, referring to the horizontal plan of the tunnel presented in Fig. 2.

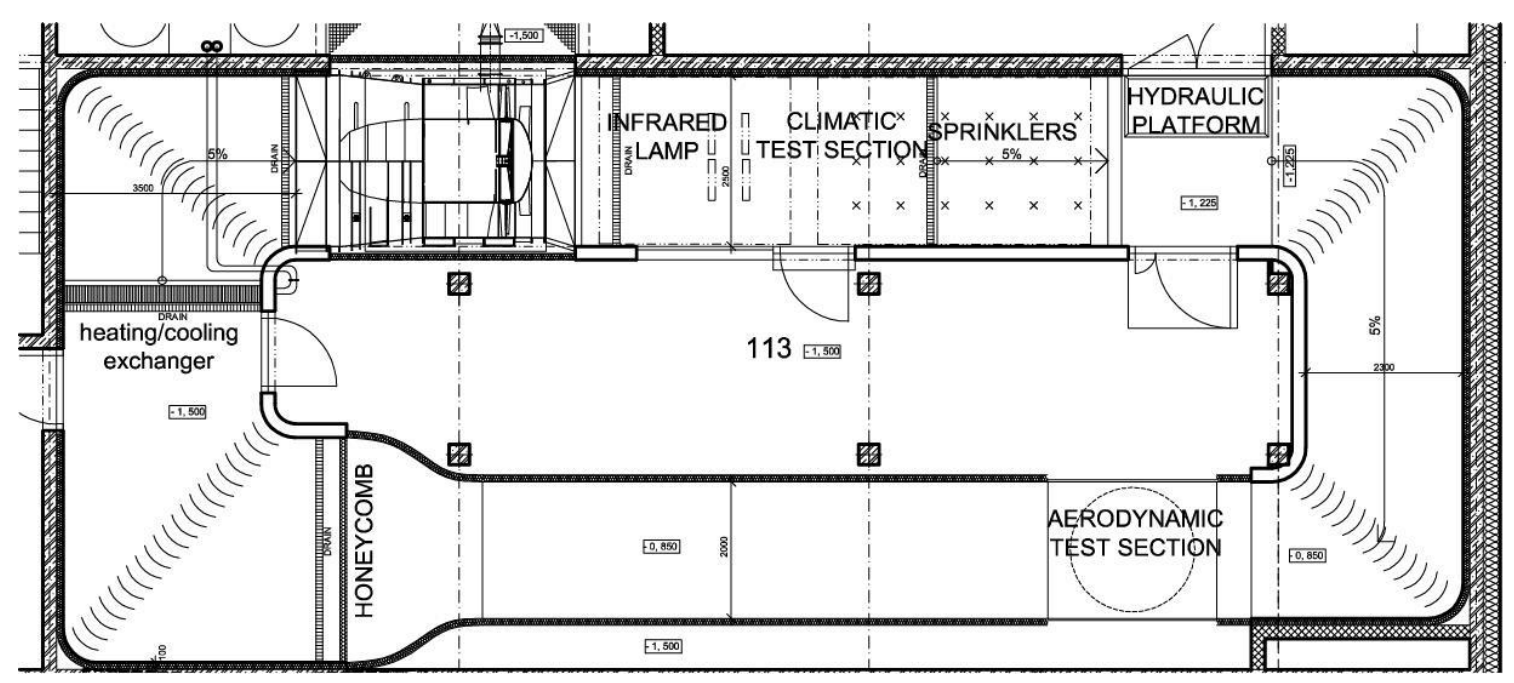

Fig. 2 Plan of the Climatic Wind Tunnel Laboratory of the Czech Academy of Sciences in Telč (website http://cet.arcchip.cz/wind-laboratory-en) 
Within the framework of the study, two tests were performed in the wind tunnel. The first was conducted in the climatic section to execute an experimental icing process of the bridge cable, and the second was conducted in the aerodynamic section to investigate the St of the stationary cable section.

\section{The icing process and its result}

The experimental icing of a $2.5 \mathrm{~m}$ long cable section with a circular cross-section and $0.160 \mathrm{~m}$ diameter was carried out. Such a diameter is typical for cables of cable supported bridges in Central Europe, where the diameters of cables start from values like $0.07 \mathrm{~m}$ up to $0.20 \mathrm{~m}$, depending on the areal density of the hangers. The cover surface of the cable was made from polyvinylchloride (PVC), which has a texture similar to that of the surface of a typical cable cover made of high-density polyethylene (HDPE). The cable model was inclined at an angle of $\alpha=30^{\circ}$ and fixed to a special frame to enable rotation relative to the airflow (Fig. 3(a)). The vertical angle $\alpha$ was chosen as a typical one for the relatively long cables of cable-supported bridges. During the experiment, the model was also inclined at an angle of $\beta=60^{\circ}$ in the horizontal plane with respect to the wind velocity direction. The horizontal yaw angle $\beta$ was chosen based on several preliminary tests as a value at which the ice ribs on the bottom side of the model were much more distinctive. The mounting position of the cable model during the icing process in the climatic section is shown in Fig. 3(b).

Different types of ice can be expected in different combinations of temperature, wind velocity, angle of wind attack and rain droplets. For the purpose of this research, the most common natural conditions in Central European geographical conditions were selected.

In such conditions, a smooth, evenly distributed ice accretion together with frozen rivulets on the cable may occur during a mild rain, a moderate temperature, i.e., slightly below $0{ }^{\circ} \mathrm{C}$, and a relatively low wind velocity, enabling the rain droplets to attach the cooled cross-section. Another reason was technical: to assure an appropriate horizontal velocity component of the water droplets. Thus, the boundary conditions during the test were as follows: the mean wind velocity was $2.8 \mathrm{~m} / \mathrm{s}$, the air temperature slightly below $0^{\circ} \mathrm{C}$, the air humidity $60 \%$ and the diameter of the sprinkler heads $2.8 \mathrm{~mm}$.

a)

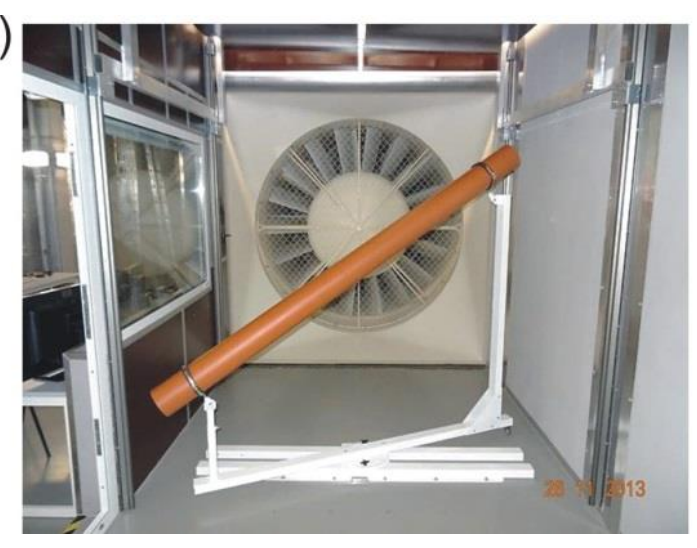

b)

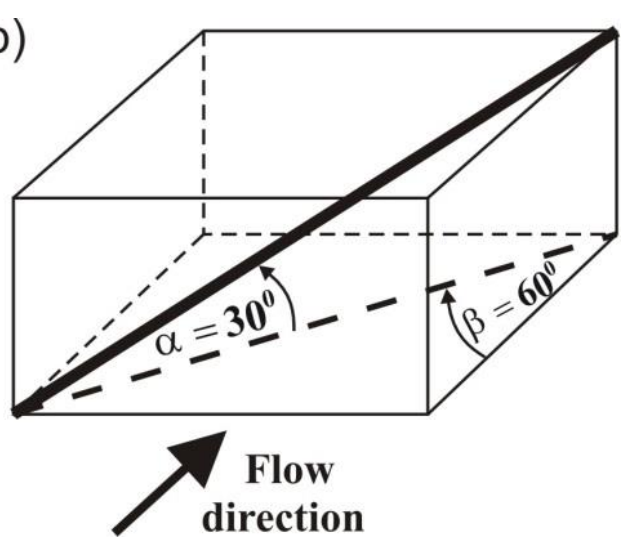

Fig. 3 (a) View of the fixation of the cable model in a special frame placed in the climatic section of the wind tunnel and (b) the attitude of the inclined cable model during the icing process 
After several preliminary tests, a 40 min cooling exposure time was selected as sufficient from the point of view of ice creation, i.e., no significant changes in the ice shape occurred thereafter. Moreover, after such an exposure time, the thickness of the ice accreted on the model surface (see Fig. 6) was very similar to the design value of ice thickness of $0.92 \mathrm{~cm}$ proposed in the current Polish Standard (1987) recommendation for almost the entire area of Poland. Before the test, several precooling procedures were tested on the cable model. Ultimately, the procedure using dry ice placed inside the tube was selected because it proved the most effective. Based on the indicators of the parameters controlling the major types of ice formation given in the ISO Standard (2001), the ice accreted on the cable was classified as wet ice accretion, i.e., the glaze-dominant type of ice. The obtained result of the ice process corresponded to the above criteria.

The final icing effect of the cable model is shown in Fig. 4. It was compared with the reference ice shape from a real situation, shown in Fig. 1. Typical ice ribs, caused by frozen rivulets on the bottom side of the model, were created and used for further examination. On the upper part of the model, the ice shape was nearly circular. The cross-section of the cable with ice became strongly nonsymmetrical (see Fig. 6(b)), with maximum dimensions of $0.192 \mathrm{~m}$ height and $0.181 \mathrm{~m}$ width. The ice mass was approximately $3.5 \mathrm{~kg} / \mathrm{m}$. The cooling and icing procedure was carried out on a scale of 1:1, therefore no thermodynamic scaling factors were considered. The effect of the surface roughness of the cable model on the flow field around the cable during the icing procedure was negligible because of the low wind velocity.

The relatively large drops were simulated, and the effect of the flow deflection near the surface of the cable on the drop trajectory was also found to be negligible. The most significant effect of the surface was on water run-off, but the real surface and the cable model surface behaved very similarly.

\section{Iced cable model for St investigations}

Immediately after the tests in the climatic section, the shape of the iced cable model was registered by a photogrammetry method combined with numerical image analysis.
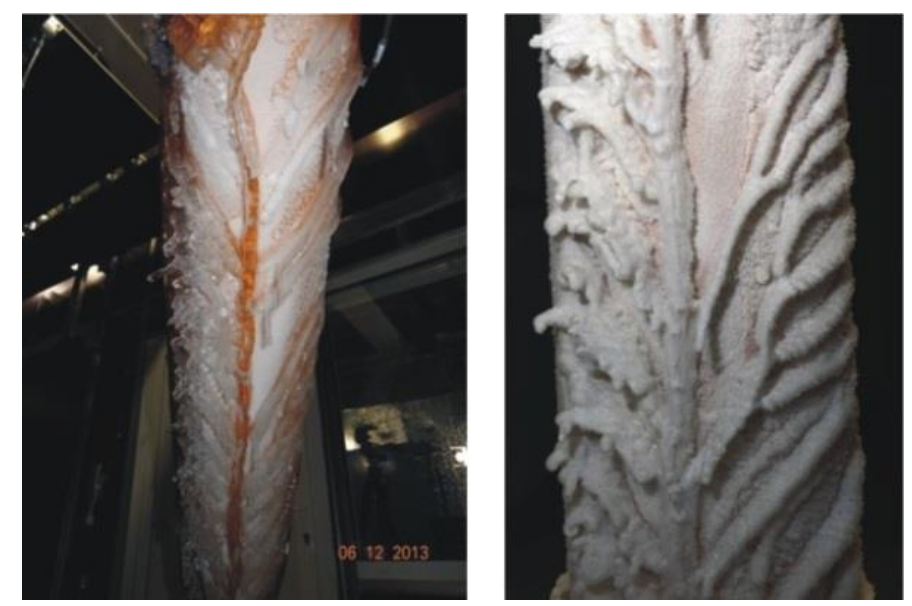

Fig. 4 Final icing effect of the cable model in the climatic section (view from the bottom side of the model) 


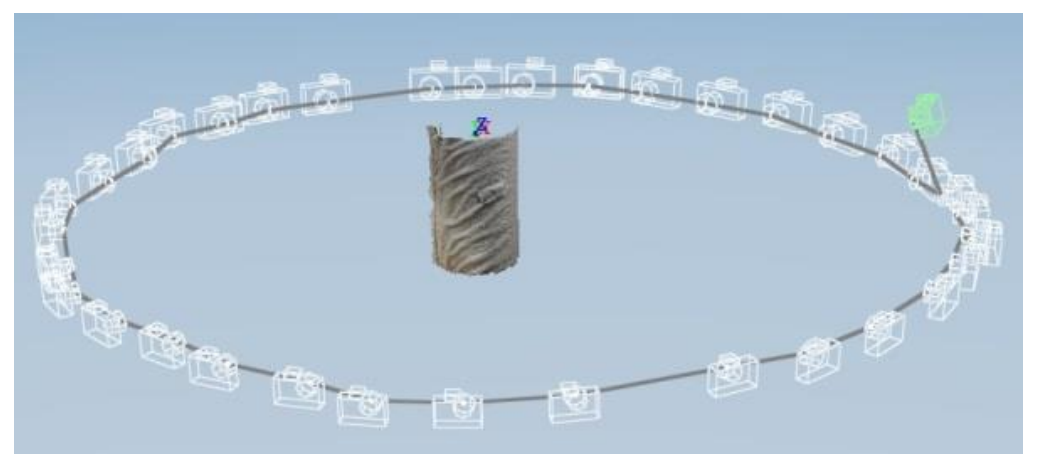

Fig. 5 Positions of the camera during a series of 35 photographs of the surface of the iced cable model

The method was realized by taking a series of 35 photographs at a distance of $1.2 \mathrm{~m}$ from the model with the angular position incremented by $\Delta \varphi$ from the interval $9^{\circ}$ to $12^{\circ}$ around the model. For taking photographs, a Nikon D600 camera with $50 \mathrm{~mm}$ f/1.4 AF-S lens was used. The positions of the camera are shown in Fig. 5. To achieve the best result during the process of photogrammetry, the surface of the ice was painted white before taking the photos. The painting was done with spray paint having minimal effect on roughness (due to very small layer thickness of the order of a few microns). Furthermore, in the paper (Taylor et al. 2006) it was indicated that the effective surface roughness is defined by dominant peaks, therefore the influence of paint roughness is negligible.

Based on the numerical image analysis of all photographs, a three-dimensional numerical model of the iced cable section was obtained (Fig. 6(a)). The contours of the selected cross-sections of the numerical model are shown in Fig. 6(b). For the wind tunnel investigations of St, one new iced cable model, shown in Fig. 7, was made at a scale of 1:1.6 using a 3D printing procedure. Consequently, the outer dimensions of the cross-section of the model were $0.120 \mathrm{~m}$ in height and $0.113 \mathrm{~m}$ in width. The principal reason of the downscaling 1:1.6 for the iced cable model was the reduction of the detrimental influence of the blockage effect on the results in the aerodynamic chamber as well as of the available testing stand. It should be noticed that the "reasonable" change of the scale was acceptable in the investigations of St, a non-dimensional number, because $R e$ remained in the very similar range. The printed model was $0.43 \mathrm{~m}$ long and it was made of polylactide plastic (PLA), which is a standard material used for 3D printing. The ice shape roughness of the printed model is the result of the ice ribs created on the bottom side (covering about $150^{\circ}$ of the circle - see Fig. 6) as well as the frozen drops created on the upper side (on the other surface of the model), which were the order of magnitude larger and dominant with respect to the flow characteristics. As stated in (Taylor et al. 2006) even advanced roughness models defined with 6 parameters, i.e. the maximum profile peak height, mean spacing of profile irregularities, a floor distance to a mean line and three for the localized hydraulic diameter variation (maximum, minimum and average), take into account only dominant (most prominent) peaks, which are, in case of the 3D printed scaled model, caused by the ice shape and the order of magnitude of few millimeters. Therefore, the influence of 3D printing roughness of a different material, which is order of magnitude less than $0.1 \mathrm{~mm}$, is negligible. Furthermore, the inaccuracy introduced by the photogrammetry method is of the same order, if not smaller, and as it is stated in 
the paper (Remondino et al. 2012) the mean deviation from ideal shapes is less than $0.1 \mathrm{~mm}$ for shapes with minimal dimensions between 100 and $200 \mathrm{~mm}$.

The relative surface roughness of the 3D printed iced cable model was $18 \%$ on the bottom side and $0.73 \%$ on the upper side of the cable model.

\section{Experimental set-up and investigation of Strouhal number}

The investigations of $S t$ were conducted in the aerodynamic section of the wind tunnel. During the tests, the sectional iced cable model was fastened motionlessly in a special frame in a horizontal position at a level $69 \mathrm{~cm}$ above the floor of the aerodynamic section, crosswise to the airflow. Two sides of the frame were equipped with transparent end-plates to ensure two-dimensional flow around the model. The height and the length of the plates were both 140.5 $\mathrm{cm}$, the width was $17 \mathrm{~cm}$ and their spacing was $47 \mathrm{~cm}$. The sketch of the experimental set-up and the model fixation in the special frame in the aerodynamic section are shown in Figs. 8 and 9.

a)

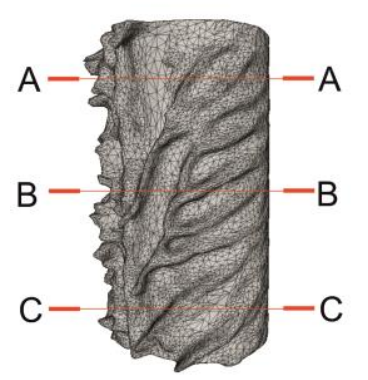

b)

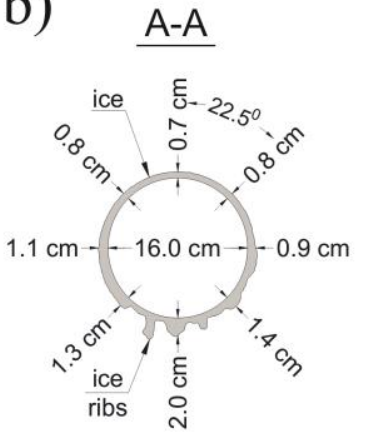

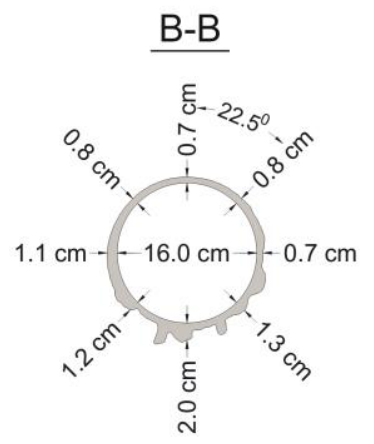

Fig. 6 (a) - Three-dimensional numerical model of the iced cable in a scale 1:1 and (b) - the contours of the selected cross-sections of the numerical model

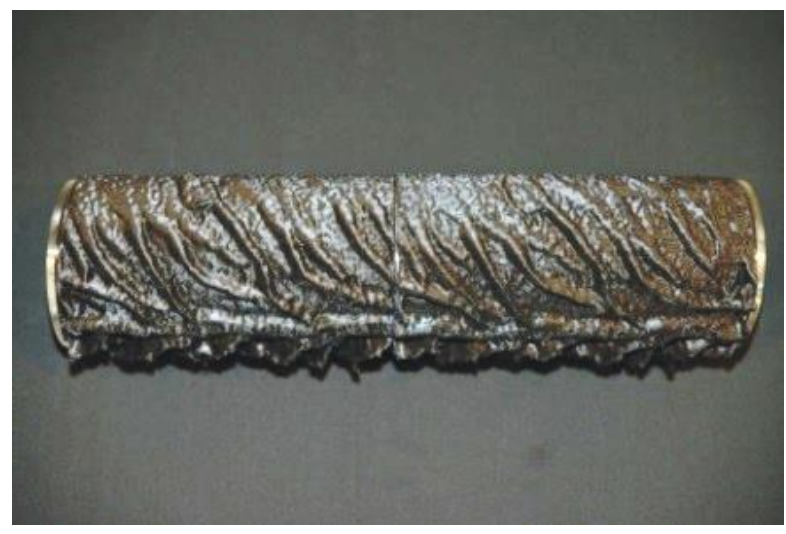

Fig. 7 Cable model with "ice" created using a 3D printing method 
a)

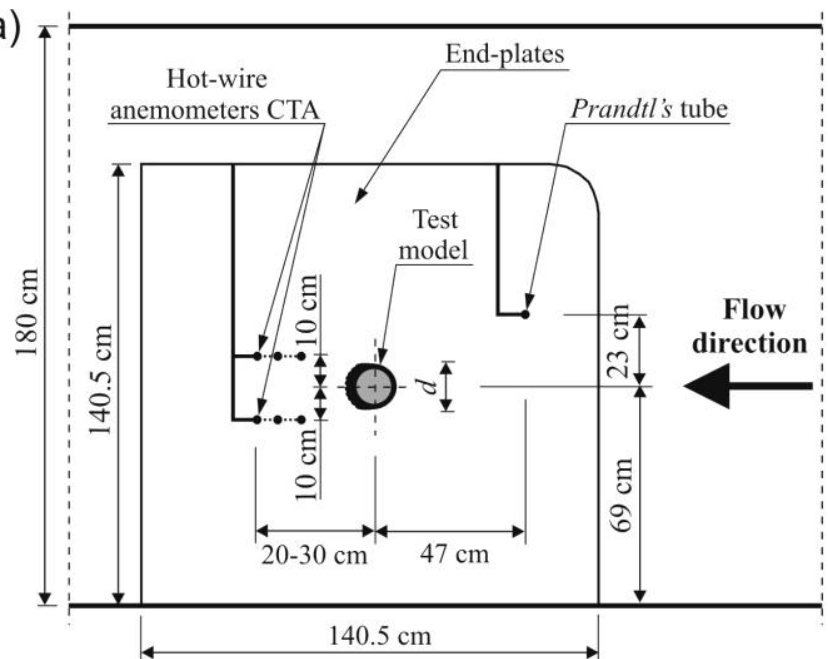

b)

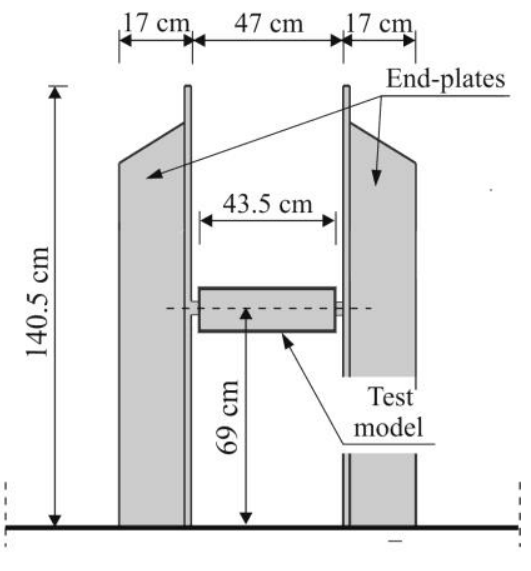

Fig. 8 Sketch of the experimental set-up in the aerodynamic section: (a) - view along the section and (b) view across the section

a)

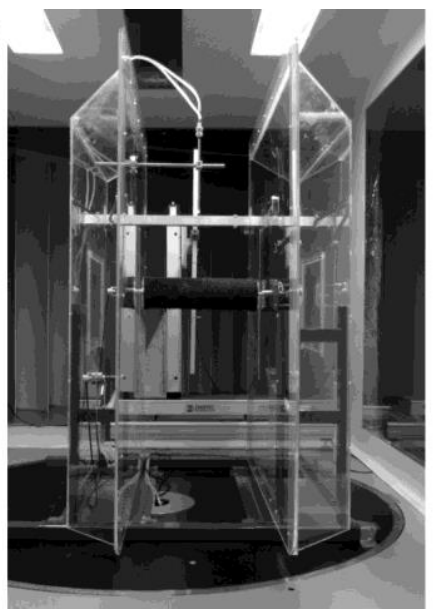

b)

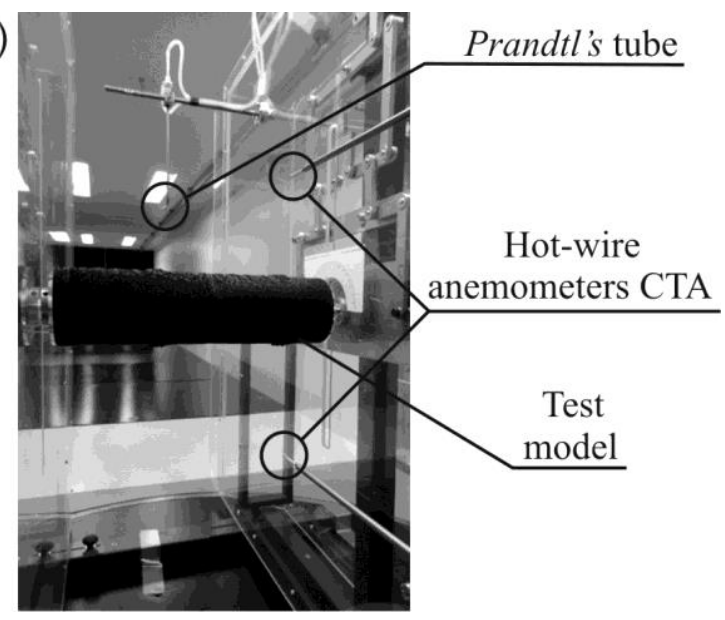

Fig. 9 (a) - View of the special frame with the iced cable model in the aerodynamic section and (b) - view of the model fixed in the special frame, the Prandtl's tube and the hot-wire anemometers CTA behind the model

The $S t$ effect was experimentally ascertained and analyzed during three tests, in which the iced cable model was orientated at three different angles to the mean wind direction. The change of the angle of wind attack was realized by rotating the model around its longitudinal axis. The principal model configurations and the reference dimension $d$ perpendicular to the airflow direction are shown in Fig. 10. In the first configuration, the ice ribs were orientated from the windward side; in the second, at the bottom side of the model; and in the third, from the leeward side. 

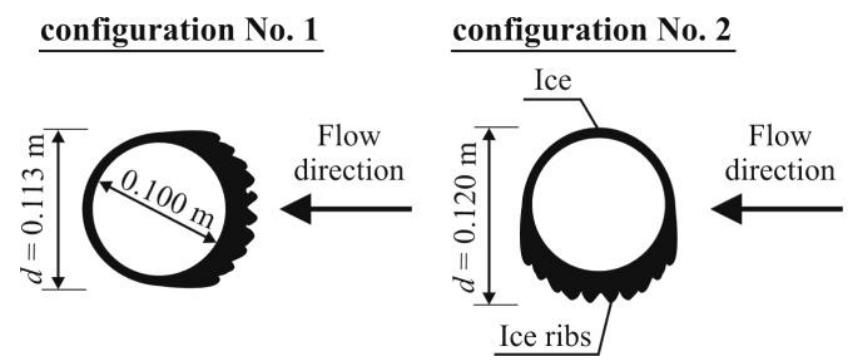

$\underline{\text { configuration No. } 3}$

Fig. 10 Model configurations and the reference dimension $d$ perpendicular to the airflow direction considered for $S t$ investigations

The $S t$ value was investigated according to the following methodology. During the tests, in each step, the reference free stream velocity in front of the model $u$ was measured by the Prandtl's tube. At the same time, the horizontal along-wind velocity component at a distance of $1.7 \cdot d$ to $2.6 \cdot d$ (20 to $30 \mathrm{~cm}$ ) behind the model, depending on the model configuration, was measured by CTA (Constant Temperature Anemometry) using two hot-wire anemometers over a $30 \mathrm{~s}$ interval with a sampling rate of $1000 \mathrm{~Hz}$. Two CTAs were fixed exactly $10 \mathrm{~cm}$ above and below the longitudinal axis of the model. Such locations of the CTA probes were established experimentally for each model configuration to place the probes directly in the wake region. The recorded airflow velocity in the wake behind the model was analysed by a Fast Fourier Transform (FFT). St was determined based on the dominant vortex-shedding frequency $f_{s}$ that was extracted from the Power Spectral Density (PSD) of the airflow velocity behind the model.

The $S t$ values were calculated from the formula

$$
S t=\frac{f_{s} \cdot d}{\bar{u}}
$$

where $f_{s}$ is the vortex-shedding frequency, $d$ is the reference dimension of the iced model perpendicular to the wind direction (see Fig. 10) and $\bar{u}$ is the mean free stream velocity in front of the model.

The $R e$ values were evaluated according to the formula

$$
\operatorname{Re}=\frac{\rho \cdot d \cdot \bar{u}}{\mu}
$$

where

$$
\rho=\frac{P}{R \cdot T} \cdot 100
$$

is the air density, $\mathrm{kg} / \mathrm{m}^{3} ; P$ is the atmospheric pressure of the air, $\mathrm{hPa} ; R=287 \mathrm{~m}^{2} /\left(\mathrm{s}^{2} \cdot \mathrm{K}\right)$ is the gas constant; $T$ is the air temperature, ${ }^{\circ} \mathrm{C}$

$$
\mu=\mu_{0}\left(\frac{T}{T_{0}}\right)^{0.76}
$$


is the dynamic viscosity of the air, Pa.s; $\mu_{0}=17.1 \cdot 10^{-6} \mathrm{~Pa} \cdot \mathrm{s}$, and $T_{0}=273 \mathrm{~K}$.

In order to calculate the exact $R e$ values, the actual air temperature $T$ and the atmospheric pressure of the air $P$ inside the aerodynamic section were measured continuously. During the tests, the air temperature inside the aerodynamic section was changeable within the range from 23.6 to $27.8^{\circ} \mathrm{C}$, and the atmospheric pressure was equal to $951.2 \mathrm{hPa}$. The tests were carried out at twelve sequential mean free stream velocities $\bar{u}$ in the range between $3.4 \mathrm{~m} / \mathrm{s}$ and $22.9 \mathrm{~m} / \mathrm{s}$, corresponding to the twelve $R e$ number regimes in the interval $R e=2.4 \cdot 10^{4}$ to $16.5 \cdot 10^{4}$. The flow was modelled as laminar with a mean turbulence intensity of the order of $3 \%$, measured in front of the model between the end-plates of the frame.

In the wind tunnel investigations, the possibility of the tunnel blockage effect on St should be taken into account if the blockage ratio is more that 6\% (West and Apelt 1982). To determine whether the blockage effect has any influence on the test results, the St of a circular smooth cylinder with a diameter of $0.10 \mathrm{~m}$ was investigated first. The mean free stream velocity $\bar{u}$ was in the range from $3.3 \mathrm{~m} / \mathrm{s}$ to $22.7 \mathrm{~m} / \mathrm{s}$, which corresponded to $R e$ in the range from $2.0 \cdot 10^{4}$ to $12.5 \cdot 10^{4}$, i.e., within the subcritical range of $R e$ for the circular smooth cylinder. The cylinder model was fixed in the same manner as the iced model (see Fig. 11(a)). The obtained St values were changing from 0.177 to 0.184 for the entire range of $R e$ that was studied. They were very similar to the value of $S t=0.18$ provided by the Eurocode Standard (2009). Thus, no detrimental blockage effect was observed in the tunnel. Fig. 11(b) shows the PSD of the airflow velocity behind the model of the circular smooth cylinder corresponding to the mean free stream velocity of $\bar{u}=15.0 \mathrm{~m} / \mathrm{s}$.

\section{Results of St investigation}

Figs. 12, 14 and 16 depict selected PSDs of the airflow velocity behind the iced cable model for configurations No. 1, 2 and 3, respectively, measured by CTA below the model at various mean free stream velocities $\bar{u}$ in the range of $3.4 \mathrm{~m} / \mathrm{s}$ to $21.0 \mathrm{~m} / \mathrm{s}$.

a)

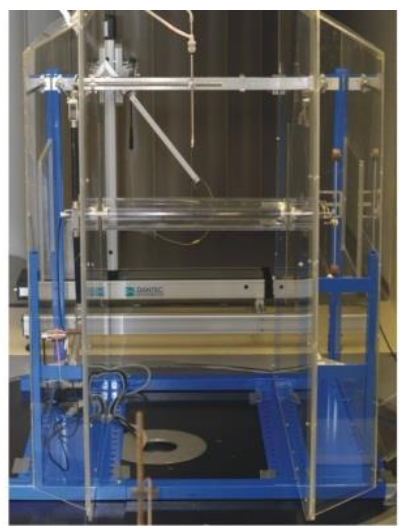

b)

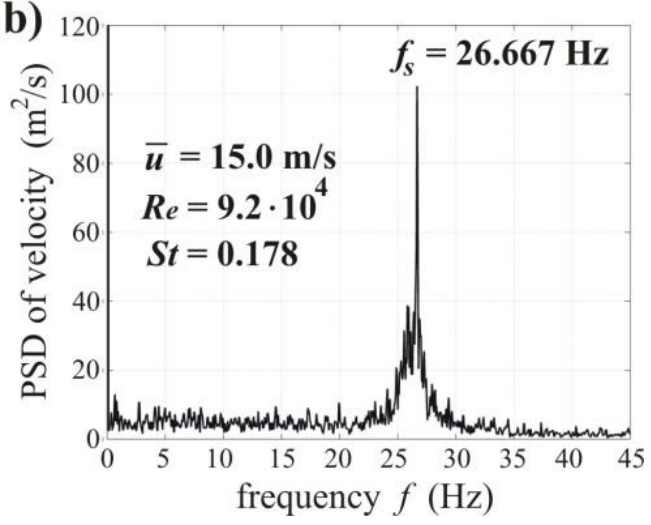

Fig. 11 (a) View of the circular smooth cylinder fixed in the special frame and (b) the PSD of the airflow velocity behind the cylinder and the dominant vortex-shedding frequency $f_{s}$ corresponding to the mean free stream velocity of $\bar{u}=15.0 \mathrm{~m} / \mathrm{s}$ 
The PSDs were estimated with a frame of 8192 data points (4096 spectrum lines). The procedure of windowing using a Hanning window with $75 \%$ overlap was applied. Figs. 13(a), 15(a) and 17(a) show the variation of the vortex shedding frequency $f_{s}$ with the mean free stream velocity $\bar{u}$, and Figs. 13(b), 15(b) and 17(b) depict the variation of $S t$ with the $R e$ values for configurations No. 1, 2 and 3, respectively. To more precisely evaluate the values of $S t$ for each model configuration, four time series of measurements of the airflow velocity in the wake behind the model at each free stream velocity $\bar{u}$ were made. Then, all values of $S t$ obtained for each configuration were approximated and were shown as a continuous line in Figs. 13(b), 15(b) and 17(b). The approximated $S t$ values were taken further as the resulting values. The obtained results were related to the results corresponding to $S t=0.18$ and indicated as a dotted line in Figs. 13, 15 and 17. In Tables 1, 2-4 and 5-7 the measured and approximated $S t$ values for configurations No. 1, 2 and 3, respectively, are presented in different flow regimes. The recognized flow regimes for each configuration are discussed in Section 7.
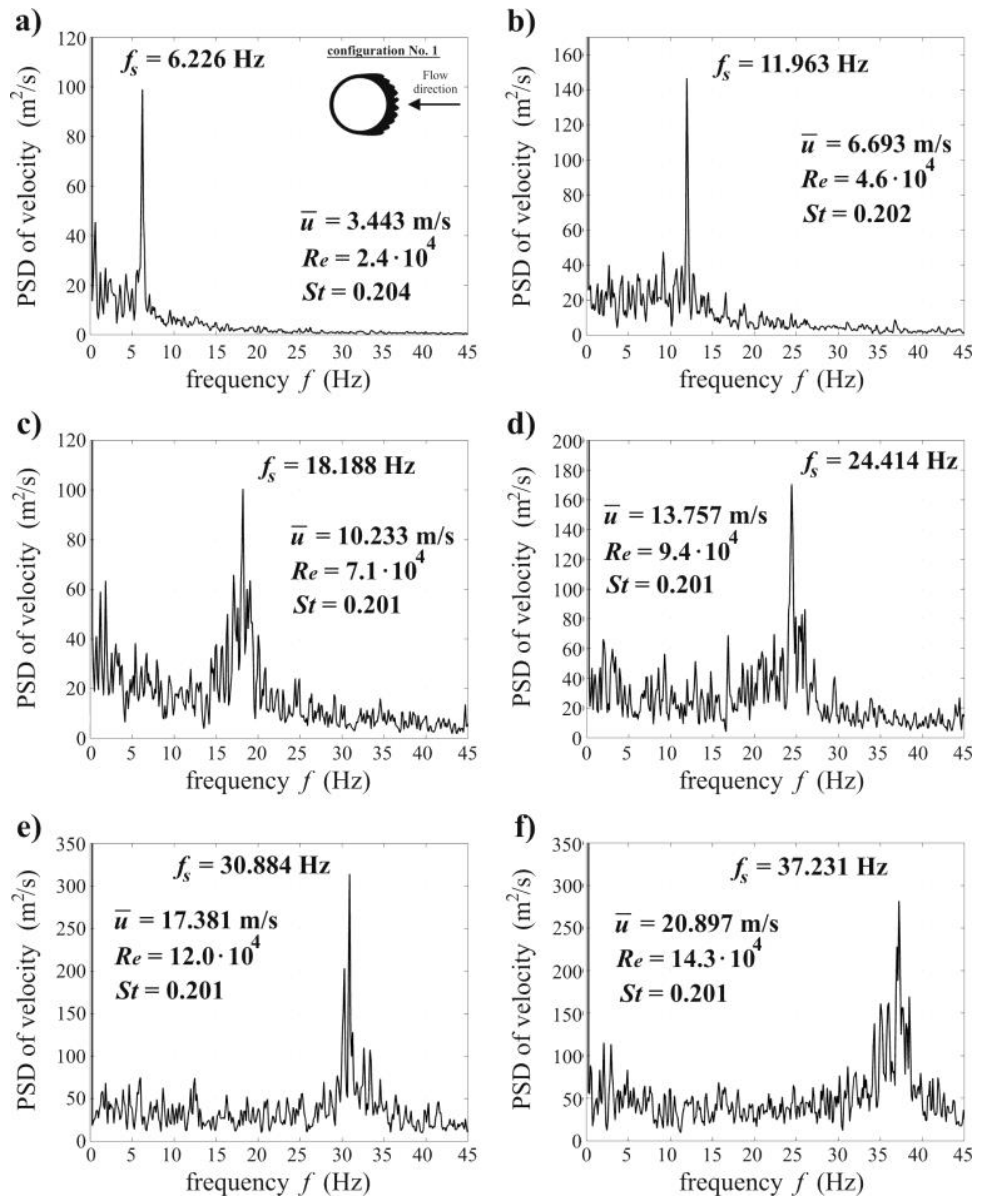

Fig. 12 Selected PSDs of the airflow velocity behind the iced cable model and dominant vortex-shedding frequencies $f_{s}$ for configuration No. 1 corresponding to mean free stream velocities: (a) $\bar{u}=3.4 \mathrm{~m} / \mathrm{s}$, (b) $\bar{u}=6.7 \mathrm{~m} / \mathrm{s}$, (c) $\bar{u}=10.2 \mathrm{~m} / \mathrm{s}$, (d) $\bar{u}=13.8 \mathrm{~m} / \mathrm{s}$, (e) $\bar{u}=17.4 \mathrm{~m} / \mathrm{s}$ and (f) $\bar{u}=20.9 \mathrm{~m} / \mathrm{s}$ 

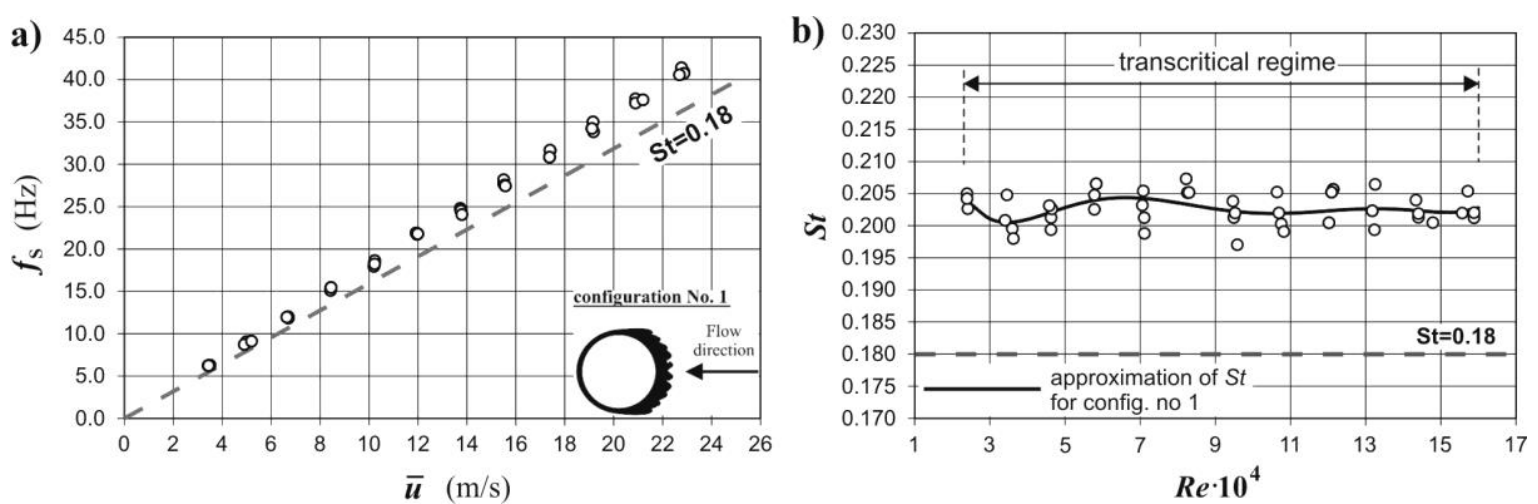

Fig. 13 (a) Variation of the vortex-shedding frequency $f_{s}$ with the mean free stream velocity in front of the model $\bar{u}$, and (b) variation of $S t$ with $R e$ for configuration No. 1 with reference to $S t=0.18$ (dotted line)
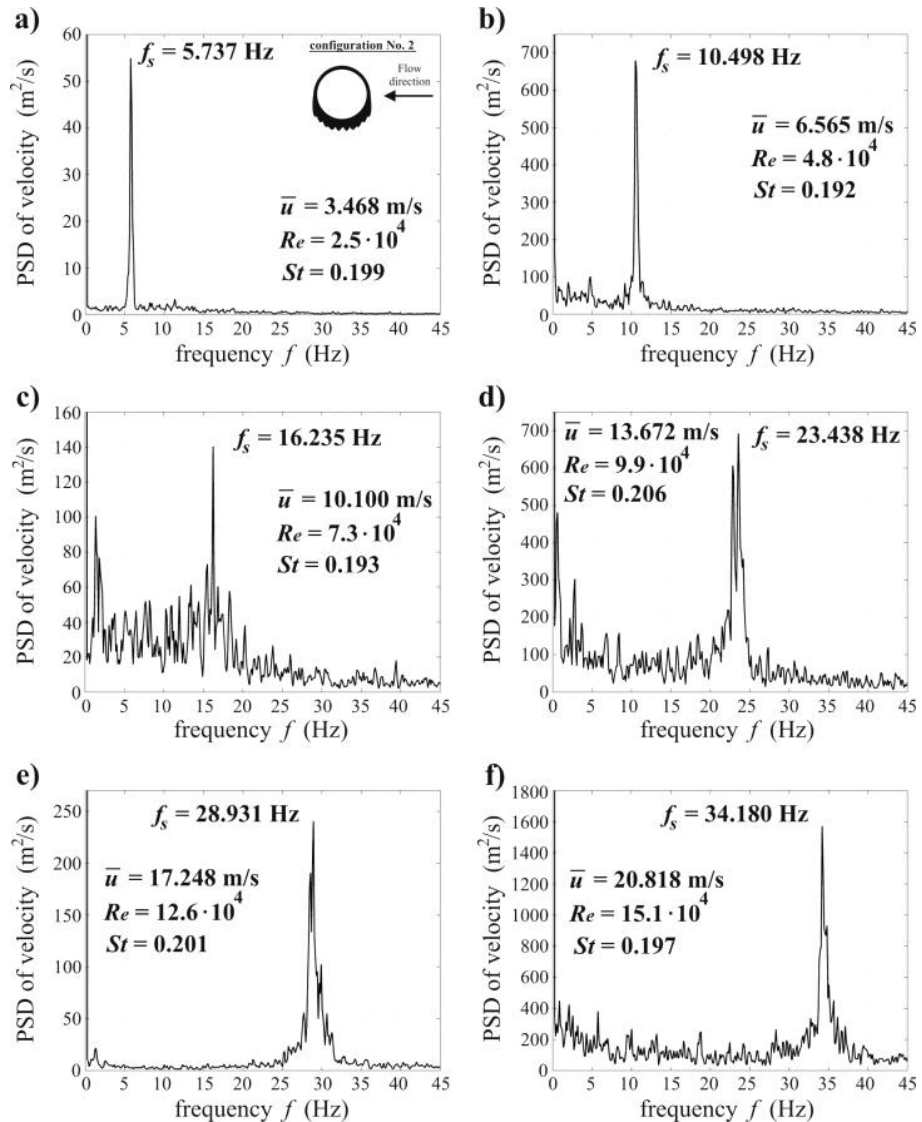

Fig. 14 Selected PSDs of the airflow velocity behind the iced cable model and dominant vortex-shedding frequencies $f_{s}$ for configuration No. 2 corresponding to mean free stream velocities: (a) $\bar{u}=3.5$ $\mathrm{m} / \mathrm{s}$, (b) $\bar{u}=6.6 \mathrm{~m} / \mathrm{s}$, (c) $\bar{u}=10.1 \mathrm{~m} / \mathrm{s}$, (d) $\bar{u}=13.7 \mathrm{~m} / \mathrm{s}$, (e) $\bar{u}=17.2 \mathrm{~m} / \mathrm{s}$ and (f) $\bar{u}=20.8 \mathrm{~m} / \mathrm{s}$ 
Table 1 Measured and approximated $S t$ values for configuration No. 1 in the transcritical flow regime

\begin{tabular}{ccccccc}
\hline \hline$R e \cdot 10^{4}$ & 2.4 & $3.4-3.6$ & 4.6 & 5.8 & 7.1 & $8.2-8.3$ \\
\hline Range of the measured $S t$ values & $0.203-0.205$ & $0.198-0.205$ & $0.199-0.203$ & $0.203-0.207$ & $0.199-0.205$ & $0.205-0.207$ \\
\hline $\begin{array}{c}\text { Approximation } \\
\text { result of } S t\end{array}$ & $\mathbf{0 . 2 0 3}$ & $\mathbf{0 . 2 0 1}$ & $\mathbf{0 . 2 0 2}$ & $\mathbf{0 . 2 0 4}$ & $\mathbf{0 . 2 0 4}$ & $\mathbf{0 . 2 0 3}$ \\
\hline
\end{tabular}

cont. Table 1

\begin{tabular}{ccccccc}
\hline \hline$R e \cdot 10^{4}$ & $9.4-9.6$ & $10.6-10.8$ & $12.0-12.1$ & 13.2 & $14.3-14.8$ & $15.6-15.9$ \\
\hline Range of the measured $S t$ values & $0.197-0.204$ & $0.199-0.205$ & $0.200-0.206$ & $0.199-0.206$ & $0.200-0.204$ & $0.201-0.205$ \\
\hline $\begin{array}{c}\text { Approximation } \\
\text { result of } S t\end{array}$ & $\mathbf{0 . 2 0 2}$ & $\mathbf{0 . 2 0 2}$ & $\mathbf{0 . 2 0 2}$ & $\mathbf{0 . 2 0 3}$ & $\mathbf{0 . 2 0 2}$ & $\mathbf{0 . 2 0 3}$ \\
\hline
\end{tabular}

Table 2 Measured and approximated $S t$ values for configuration No. 2 in the subcritical flow regime

\begin{tabular}{ccccc}
\hline \hline$R e \cdot 10^{4}$ & 2.5 & $3.5-3.6$ & 4.8 & 6.1 \\
\hline Range of the measured $S t$ values & $0.199-0.200$ & 0.197 & $0.192-0.195$ & $0.189-0.190$ \\
\hline $\begin{array}{c}\text { Approximation } \\
\text { result of } S t\end{array}$ & $\mathbf{0 . 2 0 0}$ & $\mathbf{0 . 1 9 7}$ & $\mathbf{0 . 1 9 4}$ & $\mathbf{0 . 1 8 9}$ \\
\hline
\end{tabular}
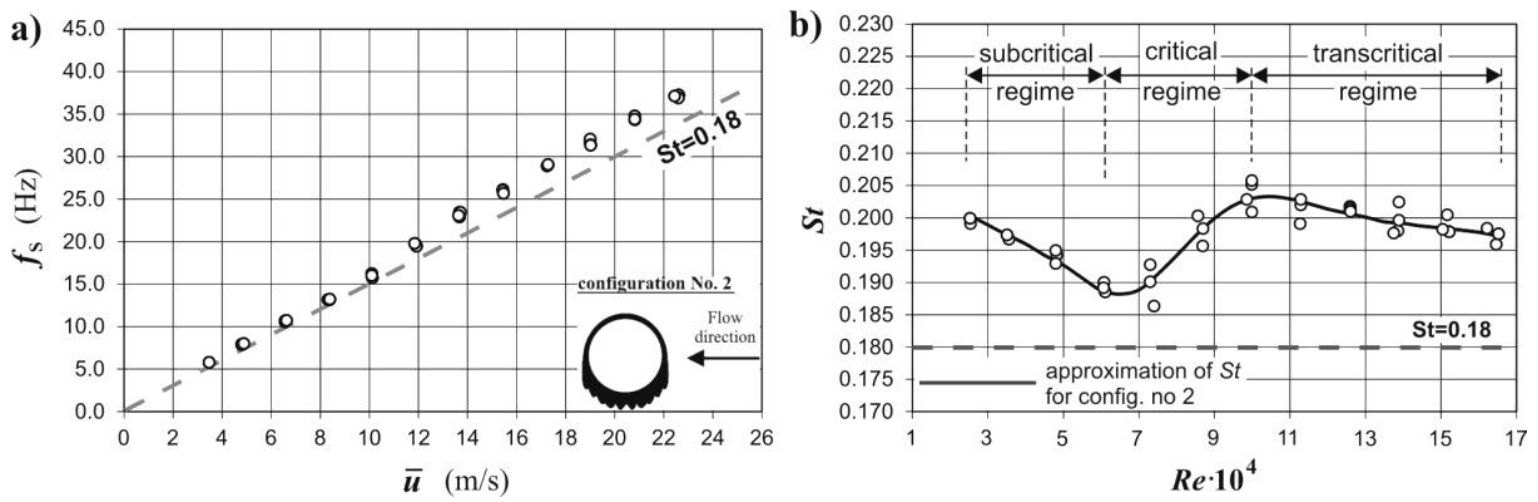

Fig. 15 (a) Variation of the vortex-shedding frequency $f_{s}$ with the mean free stream velocity in front of the model $\bar{u}$, and (b) variation of $S t$ with $R e$ for configuration No. 2 with reference to $S t=0.18$ (dotted line) 
Table 3 Measured and approximated $S t$ values for configuration No. 2 in the critical flow regime

\begin{tabular}{ccccc}
\hline \hline$R e \cdot 10^{4}$ & 6.1 & $7.3-7.4$ & $8.6-8.7$ & $9.9-10.0$ \\
\hline Range of the measured $S t$ values & $0.189-0.190$ & $0.186-0.193$ & $0.196-0.200$ & $0.201-0.206$ \\
\hline $\begin{array}{l}\text { Approximation } \\
\text { result of } S t\end{array}$ & $\mathbf{0 . 1 8 9}$ & $\mathbf{0 . 1 9 0}$ & $\mathbf{0 . 1 9 8}$ & $\mathbf{0 . 2 0 3}$ \\
\hline
\end{tabular}

Table 4 Measured and approximated St values for configuration No. 2 in the transcritical flow regime

\begin{tabular}{ccccccc}
\hline \hline$R e \cdot 10^{4}$ & $9.9-10.0$ & 11.3 & 12.6 & $13.7-13.9$ & $15.0-15.2$ & $16.2-16.5$ \\
\hline Range of the measured $S t$ values & $0.201-0.206$ & $0.199-0.203$ & $0.201-0.202$ & $0.198-0.202$ & $0.197-0.200$ & $0.196-0.198$ \\
\hline $\begin{array}{c}\text { Approximation } \\
\text { result of } S t\end{array}$ & $\mathbf{0 . 2 0 3}$ & $\mathbf{0 . 2 0 2}$ & $\mathbf{0 . 2 0 1}$ & $\mathbf{0 . 1 9 9}$ & $\mathbf{0 . 1 9 8}$ & $\mathbf{0 . 1 9 7}$ \\
\hline
\end{tabular}

Table 5 Measured and approximated St values for configuration No. 3 in the subcritical flow regime

\begin{tabular}{cccc}
\hline \hline$R e \cdot 10^{4}$ & 2.4 & $3.3-3.4$ & $4.6-4.7$ \\
\hline Range of the measured $S t$ values & $0.187-0.190$ & $0.185-0.190$ & $0.185-0.190$ \\
\hline $\begin{array}{c}\text { Approximation } \\
\text { result of } S t\end{array}$ & $\mathbf{0 . 1 8 8}$ & $\mathbf{0 . 1 8 7}$ & $\mathbf{0 . 1 8 7}$ \\
\hline
\end{tabular}

Table 6 Measured and approximated St values for configuration No. 3 in the critical flow regime

\begin{tabular}{cccccc}
\hline \hline$R e \cdot 10^{4}$ & $4.6-4.7$ & $5.8-5.9$ & $7.0-7.2$ & $8.3-8.4$ & $9.5-9.7$ \\
\hline Range of the measured $S t$ values & $0.185-0.190$ & $0.192-0.195$ & $0.196-0.202$ & $0.211-0.216$ & $0.214-0.219$ \\
\hline $\begin{array}{c}\text { Approximation } \\
\text { result of } S t\end{array}$ & $\mathbf{0 . 1 8 7}$ & $\mathbf{0 . 1 9 2}$ & $\mathbf{0 . 1 9 9}$ & $\mathbf{0 . 2 1 4}$ & $\mathbf{0 . 2 1 6}$ \\
\hline
\end{tabular}

Table 7 Measured and approximated St values for configuration No. 3 in the transcritical flow regime

\begin{tabular}{ccccccc}
\hline \hline$R e \cdot 10^{4}$ & $9.5-9.7$ & $10.7-10.9$ & $12.0-12.2$ & $13.2-13.4$ & $14.4-14.7$ & $15.7-15.9$ \\
\hline Range of the measured $S t$ values & $0.214-0.219$ & $0.211-0.215$ & $0.212-0.214$ & $0.210-0.213$ & $0.205-0.207$ & $0.205-0.207$ \\
\hline $\begin{array}{c}\text { Approximation } \\
\text { result of } S t\end{array}$ & $\mathbf{0 . 2 1 6}$ & $\mathbf{0 . 2 1 5}$ & $\mathbf{0 . 2 1 3}$ & $\mathbf{0 . 2 1 0}$ & $\mathbf{0 . 2 0 7}$ & $\mathbf{0 . 2 0 6}$ \\
\hline
\end{tabular}


a)

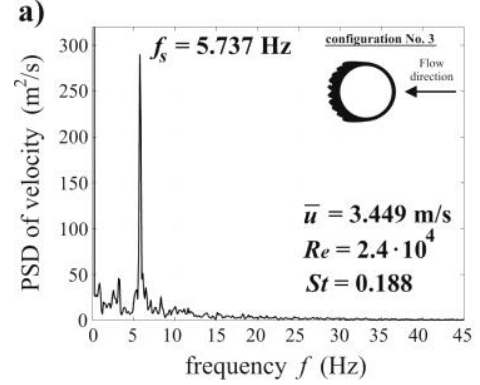

c)

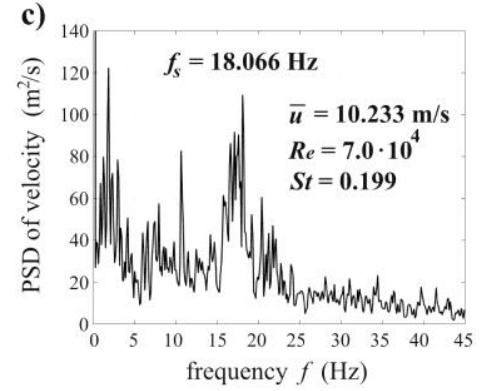

e)

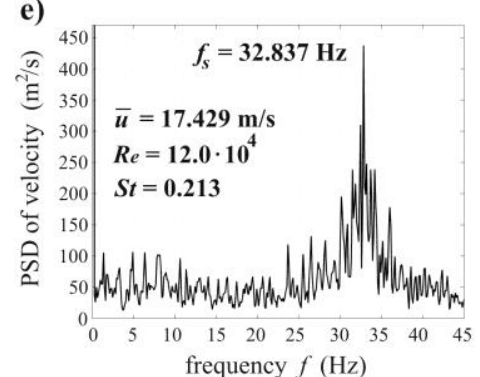

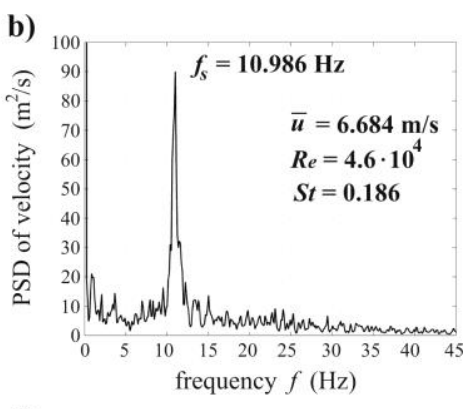

d)
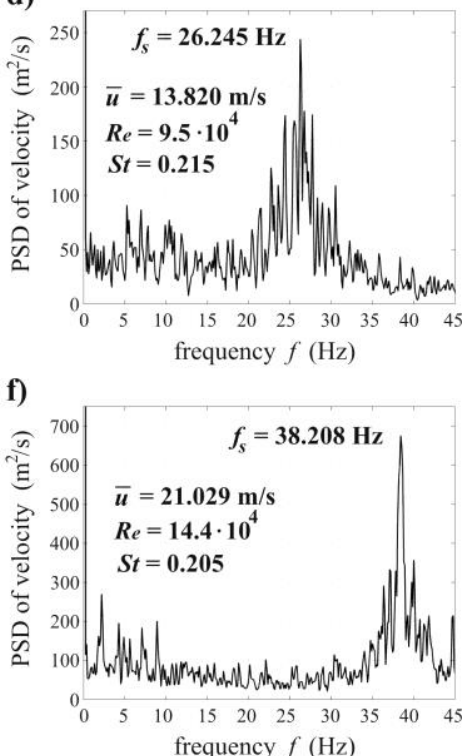

Fig. 16 Selected PSDs of the airflow velocity behind the iced cable model and dominant vortex-shedding frequencies $f_{s}$ for configuration No. 3 , corresponding to the mean free stream velocities: (a) $\bar{u}=3.4$ $\mathrm{m} / \mathrm{s}$, (b) $\bar{u}=6.7 \mathrm{~m} / \mathrm{s}$, (c) $\bar{u}=10.2 \mathrm{~m} / \mathrm{s}$, (d) $\bar{u}=13.8 \mathrm{~m} / \mathrm{s}$, (e) $\bar{u}=17.4 \mathrm{~m} / \mathrm{s}$ and (f) $\bar{u}=21.0 \mathrm{~m} / \mathrm{s}$
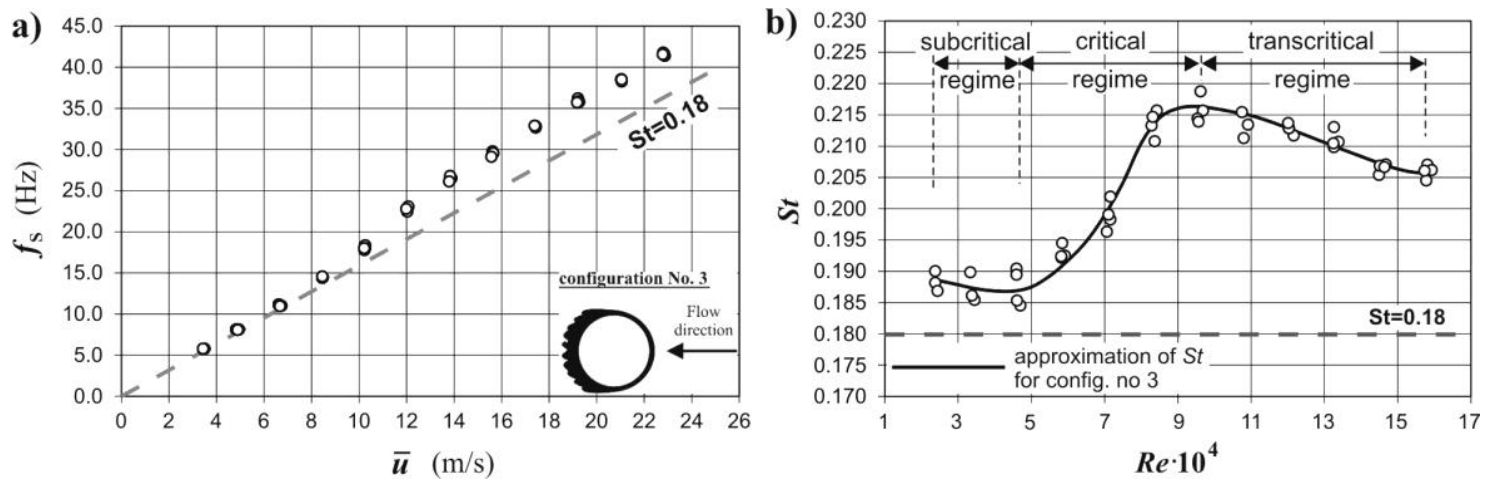

Fig. 17 (a) Variation of the vortex-shedding frequency $f_{s}$ with the mean free stream velocity in front of the model $\bar{u}$, and (b) variation of $S t$ with $R e$ for configuration No. 3 with reference to $S t=0.18$ (dotted line) 


\section{Discussion}

It is well known (Buresti 1981, Pantazopoulos 1994, Niemann and Hölscher 1990) that in the case of a smooth circular cylinder in uniform flow, the studied $R e$ range is in the subcritical regime $\left(300<R e<1.5 \cdot 10^{5}\right)$, in which the boundary-layer flow at the cylinder surface is laminar, a vortices arise from alternate sides of the cylinder within a narrow frequency band and the spectrum of vortex-shedding has a characteristic maximum at the predominant frequency corresponding to the $S t$ value of about 0.18 - see Fig. 11(b). In the critical and supercritical regimes $\left(1.5 \cdot 10^{5}<R e<\right.$ $3.5 \cdot 10^{6}$ ), the boundary layer becomes turbulent, and there is no periodic vortex excitation, so multiple spectral peaks in the spectrum with a frequency broadband occur. In this regime, St has a greatest value between $0.4-0.5$. In the transcritical regime $\left(R e>3.5 \cdot 10^{6}\right)$, the boundary-layer flow is turbulent, a quasi-periodic vortex excitation appears and the spectrum with a relatively narrow frequency band has one clear spectral peak corresponding to $S t$ in the range of $0.2-0.3$. In this case, the spectral bandwidth is slightly wider than in the subcritical range (Pantazopoulos 1994).

It should be noted that previous wind tunnel studies presented in the paper (Buresti 1981) show that the increased surface roughness of the cylinder as well as the increased turbulence intensity of the free stream induce transition to the critical and the transcritical regimes at a lower $R e$. Moreover, the critical regime can be strongly reduced and it may almost disappear in the case of highly roughened cylinders. Thus, the effect of the change of the angle of wind attack on the studied iced cable model at various $R e$ on the $S t$ values is reflecting the experimental data by Buresti (1981) obtained at different surface roughness of the cylinder. Taking into account the above statements and based on the St results (see Figs. 13(b), 15(b) and 17(b)) as well as the pattern of the PSD functions of the airflow velocity in the wake behind the iced cable model (see Figs. 12, 14 and 16) the major Re regimes for configurations No. 1, 2, and 3 were recognized and are described below.

In configuration No. 1, in the entire range of $R e$ that was studied, the spectral bandwidth of the predominant peak (see Fig. 12) is clearly wider than in the case of the circular smooth cylinder (see Fig. 11(b)). Thus, it can be stated that from the small $R e$ values $\left(R e \geq 2.4 \cdot 10^{4}\right)$, the character of the wake behind the iced cable model is appropriate to the wake of the smooth cylinder in the transcritical regime.

In configuration No. 2 , the studied $R e$ range should be divided into three major ranges correspond to the subcritical, critical and transcritical flow regimes (Fig. 15(b)). In the first $R e$ range $\left(2.5 \cdot 10^{4}<R e<6.1 \cdot 10^{4}\right)$, the spectra have one peak with a clearly narrow bandwidth (see Fig. 14(a) and 14(b)), and thus, the subcritical flow regime can be distinguished. In the range of $R e=$ $6.1 \cdot 10^{4}-10.0 \cdot 10^{4}$, multi-dominant frequency peaks with a frequency broadband occur in the spectrum (see Fig. 14(c)), and thus, the critical regime was recognized. In the range of $R e=$ $10.0 \cdot 10^{4}-16.5 \cdot 10^{4}$, spectra with a relatively narrow frequency band appear again (see Fig. 14(d)-14(f)), indicating the transcritical regime of the airflow.

As in the previous configuration, for configuration No. 3, there can also be distinguished three regimes of $\operatorname{Re}$ (Fig. 17(b)), i.e., in the range of $R e=2.4 \cdot 10^{4}-4.6 \cdot 10^{4}$, the subcritical regime (corresponding to the PSDs in Fig. 16(a) and 16(b)); in the range of $R e=4.6 \cdot 10^{4}-9.5 \cdot 10^{4}$, the critical regime (corresponding to the PSD in Fig. 16(c)); and in the range of $R e=9.5 \cdot 10^{4}$ 15.9 $10^{4}$, the transcritical regime (corresponding to the PSDs in Fig. 16(d)-16(f)).

The aerodynamic investigations were conducted under the assumption that the mean wind direction during the icing process is independent of the wind direction during the investigations of $S t$. Thus, the investigations of $S t$ were conducted with respect to three principal angles of wind 
attack, perpendicular to the longitudinal axis of the model. In early experiments (Surry and Surry 1967), the effect of cable inclination on $S t$ of a rigid circular cylinder was examined. It was found that $S t$ based on the velocity component normal (perpendicular) to the cylinder axis remains constant to inclination at an angle of $\alpha$ between $30^{\circ}$ and $90^{\circ}$. Based on such observations the following statements can be formulated in practical cases: (1) for wind along the bridge, i.e., at $\beta=180^{\circ}$ or $\beta=0^{\circ}$, the $S t$ results obtained for configuration No. 1 or No. 3, respectively, should be taken into account with the reference Reynolds number $R e_{\text {ref }}$ related to the mean wind velocity in the horizontal plane, calculated according to the formula

$$
R e_{r e f}=\frac{R e}{\sin (\alpha)}
$$

and (2) for wind across the bridge, i.e. at $\beta=90^{\circ}$, the cable inclination is unimportant and the $S t$ results obtained for configuration No. 2 should be taken into account with $R e_{r e f}=R e$.

\section{Conclusions}

The experimental accretion of ice on an inclined cable model of a cable-supported bridge was carried out in the Climatic Wind Tunnel Laboratory of the Czech Academy of Sciences in Telč. The ice accretion process produced an asymmetric and irregularly iced cross-section of the cable model with rounded edges of the ice ribs accreted on the bottom side of the model (with a maximal surface roughness of 18\%) and with a quasi-circular shape on its upper part (with a minimal surface roughness of $0.73 \%$ ). St was investigated for the stationary iced cable model with respect to three principal angles of wind attack within the range of $R e$ between $2.4 \cdot 10^{4}$ and $16.5 \cdot 10^{4}$.

St determined for configuration No. 1 varies in the range from 0.201 to 0.204 and seems to be independent of $R e$ in the range that was studied (Fig. 13(b)). All the $S t$ values obtained are $12 \%$ to $13 \%$ higher than $S t=0.18$, used as a reference. The variability of the $S t$ values for configuration No. 2 can be incidental and can be caused by the randomness of the vortex excitation. Nevertheless, the differences between the dominant vortex-shedding frequencies measured in the wake above and below the model did not exceed $5 \%$.

St determined for configuration No. 2 depends on Re (Fig. 15(b)). Initially, in the range of $R e=2.5 \cdot 10^{4}-6.1 \cdot 10^{4}$, the $S t$ values decrease linearly from $S t=0.200$ to 0.189. In the range of $R e$ $=6.1 \cdot 10^{4}-9.9 \cdot 10^{4}, S t$ suddenly increases to $S t=0.203$, and for $R e$ greater than $9.9 \cdot 10^{4}$, St again decreases to $S t=0.197$. As in configuration No. 1, the differences between the dominant vortex-shedding frequencies obtained from the measurements using CTA located above and below the model did not exceed 5\%.

St determined for configuration No. 3 strictly depends on Re (Fig. 17(b)). St values were initially in the range of $S t=0.187-0.188$ for $R e=2.4 \cdot 10^{4}-4.6 \cdot 10^{4}$, while in the range of $R e=$ $4.6 \cdot 10^{4}-9.5 \cdot 10^{4}$, St suddenly increased to the maximum value of $S t=0.216$. In the range of $R e=$ 9.5.10 $-15.9 \cdot 10^{4}$, St decreases from $S t=0.216$ to 0.206 . The differences between the dominant vortex-shedding frequencies obtained from the measurements using CTA located above and below the model did not exceed $6 \%$. 


\section{Acknowledgments}

This work was created with support from project No. LO1219 under the Ministry of Education, Youth and Sports National sustainability programme 1 and partially with the support from project No. GAČR 13-34405J and 14-12892S (Section 3). Marcin Tatara is a scholar of the "PhD Scholarships - investment in the scientific staff Opole Voivodeship II" project co-funded by the European Union within the European Social Fund.

\section{References}

Bartoli, G., Cluni, F., Gusella, V. and Procino, L. (2006), "Dynamics of cable under wind action: Wind tunnel experimental analysis", J. Wind Eng. Ind. Aerod., 94(5), 259-273.

Buresti G. (1981), "The effect of surface roughness on the flow regime around circular cylinders", J. Wind Eng. Ind. Aerod., 8(1-2), 105-114.

Demartino, C., Georgakis, C.T. and Ricciardelli, F. (2013a), "Experimental study of the effect of icing on the aerodynamics of circular cylinders - Part II: Inclined flow", Proceedings of the 6th European and African Wind Engineering Conference, Robinson College, Cambridge, UK, July.

Demartino, C., Koss, H. and Ricciardelli, F. (2013b), "Experimental study of the effect of icing on the aerodynamics of circular cylinders - Part I: Cross flow", Proceedings of the 6th European and African Wind Engineering Conference, Robinson College, Cambridge, UK, July.

Demartino, C., Koss, H.H., Georgakis, C.T. and Ricciardelli, F. (2015), "Effects of ice accretion on the aerodynamics of bridge cables", J. Wind Eng. Ind. Aerod., 138, 98-119.

Demartino, C. and Ricciardelli, F. (2015), "Aerodynamic stability of ice-accreted bridge cables", J. Fluid Struct., 52, 81-100.

Dyrbye, C. and Hansen, S.O. (1997), Wind loads on structures, John Wiley \& Sons Ltd., New York, USA.

Eurocode 1 (2009), Action on structures - part 1-4: General action - Wind action.

Flaga, A. (2008), Wind engineering, Arkady, Warsaw (in Polish).

Flaga, A. (2011), Footbridges, WKŁ, Warsaw (in Polish).

Fu, P., Farzaneh, M. and Bouchard, G. (2006), "Two-dimensional modelling of the ice accretion process on transmission line wires and conductors", Cold Reg. Sci. Technol., 46(2), 132-146.

Gjelstrup, H., Georgakis, C.T. and Larsen, A. (2007), "A preliminary investigation of the hanger vibrations on the Great Belt East Bridge", Proceedings of the 7th International Symposium on Cable Dynamics, Vienna, Austria, December.

Gjelstrup, H., Georgakis, C.T. and Larsen, A. (2012), “An evaluation of iced bridge hanger vibrations through wind tunnel testing and quasi-steady theory", Wind Struct., 15(5), 385-407.

Gurung, C.B., Yamaguchi, H. and Yukino, T. (2002), "Identification of large amplitude wind-induced vibration of ice accreted transmission lines based on field observed data", Eng. Struct., 24(2), 179-188.

Hartog, J.P.D. (1932), "Transmission-line vibration due to sleet", Inst. Electrical Engineers, 51(4), 1074-1086.

http://cet.arcchip.cz/wind-laboratory-en (last visit in April, 2015).

http://www.toledoblade.com/gallery/Ice-closes-Skyway (last visit in January, 2014).

Huang, H., Li, J., Li, Z., Yan, Z. and Liu, S. (2011), "Test study on transmission line's ice accretion", Proceedings of the 13th International Conference on Wind Engineering, Amsterdam, Netherlands, July.

Impollonia, N., Ricciardi, G. and Saitta, F. (2011), "Vibrations of inclined cables under skew wind", Int. J. Nonlinear. Mech., 46(7), 907-918.

ISO 12494 (2001), Atmospheric icing of structures, Int. Standard.

Jakobsen, J.B., Andersen, T.L., Macdonald, J.H.G., Nikitas, N., Larose, G.L., Savage, M.G. and McAuliffe, B.R. (2012), "Wind-induced response and excitation characteristics of an inclined cable model in the 
critical Reynolds number range", J. Wind Eng. Ind. Aerod., 110, 100-112.

Koss, H., Gjelstrup, H. and Georgakis, C.T. (2012), "Experimental study of ice accretion on circular cylinders at moderate low temperatures", J. Wind Eng. Ind. Aerod., 104-106, 540-546.

Koss, H., Henningsen, J.F. and Olsen, I. (2013), "Influence of icing on bridge cable aerodynamics", Proceedings of the 15th International Workshop on Atmospheric Icing of Structures (IWAIS XV), St. John's, Newfoundland and Labrador, Canada, September.

Koss, H. and Lund, M.S.M. (2013), "Experimental investigation of aerodynamic instability of iced bridge cable sections", Proceedings of the 6th European and African Wind Engineering Conference, Robinson College, Cambridge, UK, July.

Makkonen, L. (1998), "Modeling power line icing in freezing precipitation", Atmos. Res., 46(1-2), 131-142.

Matsumoto, M., Yagi, T., Shigemura, Y. and Tsushima, D. (2001), "Vortex-induced cable vibration of cable-stayed bridges at high reduced wind velocity", J. Wind Eng. Ind. Aerod., 89(7-8), 633-647.

Niemann, H.J. and Hölscher, N. (1990), "A review of recent experiments on the flow past circular cylinders", J. Wind Eng. Ind. Aerod., 33, 197-209.

Pantazopoulos, M.S. (1994), "Vortex-induced vibration parameters: critical review", Proceedings of the 17th International Conference on Offshore Mechanics and Arctic Engineering, Osaka, Japan, June.

PN-87/B-02013 (1987), Actions on building structures. Variable environmental actions, Atmospheric icing action, Polish Standard (in Polish).

Remondino, F., Del Pizzo, S., Kersten, T.P. and Troisi, S. (2012), "Low-Cost and Open-Source Solutions for Automated Image Orientation - a critical overview", Proceedings of the 4th International Conference on Progress in Cultural Heritage Preservation.

Surry, J. and Surry, D. (1967), The effect of inclination on the Strouhal number and other wake properties of circular cylinders at subcritical Reynolds numbers, Technical Report, UTIAS Technical note No. 116, Institute for Aerospace Studies, University of Toronto.

Taylor, J.B., Carrano, L.A. and Kandlikar, S.G. (2006), "Characterization of the effect of surface roughness and texture on fluid flow-past, present, and future", Int. J. Therm. Sci., 45(10), 962-968.

Wagner, T. and Peil, U. (2011), "Ice formation on transmission line cables in tandem arrangement", Proceedings of the 13th International Conference on Wind Engineering, Amsterdam, Netherlands, July.

Wardlaw, R.L. (1990), "Wind effects on bridges", J. Wind Eng. Ind. Aerod., 33(1-2), 301-312.

Waris, M.B., Ishihara, T. and Sarwar, M.W. (2008), "Galloping response prediction of ice-accreted transmission lines", Proceedings of the 4th International Conference on Advances in Wind and Structures, Seogwipo, Jeju, Korea, May.

West, G.S. and Apelt, C.J. (1982), "The effects of tunnel blockage and aspect ratio on the mean flow past a circular cylinder with Reynolds numbers between $10^{4}$ and 10 ${ }^{5}$ ", J. Fluid Mech., 114, 361-377.

Zdero, R. and Turan, O.F. (2010), "The effect of surface strands, angle of attack, and ice accretion on the flow field around electrical power cables", J. Wind Eng. Ind. Aerod., 98(10-11), 672-678.

Zhitao, Y., Zhengliang, L., Eric, S. and William, E.L. (2013), "Galloping of a single iced conductor based on curved-beam theory", J. Wind Eng. Ind. Aerod., 123, 77-87.

$C C$ 